\title{
JIS Definition Identified More Malaysian Adults with Metabolic Syndrome Compared to the NCEP-ATP III and IDF Criteria
}

\author{
Anis Safura Ramli, ${ }^{1,2}$ Aqil Mohammad Daher, ${ }^{2,3}$ Mohamed Noor Khan Nor-Ashikin, ${ }^{2,4}$ \\ Nafiza Mat-Nasir,, Kien Keat Ng, ${ }^{1,2}$ Maizatullifah Miskan, ${ }^{1,2}$ Krishnapillai S. Ambigga, ${ }^{1,2}$ \\ Farnaza Ariffin, ${ }^{1,2}$ Md Yasin Mazapuspavina, ${ }^{1,2}$ Suraya Abdul-Razak, ${ }^{1,2}$ \\ Hasidah Abdul-Hamid, ,,2 Fadhlina Abd-Majid, ${ }^{2}$ Najmin Abu-Bakar, ${ }^{2}$ \\ Hapizah Nawawi, ${ }^{2,5}$ and Khalid Yusoff ${ }^{2,6}$ \\ ${ }^{1}$ Primary Care Medicine Discipline, Faculty of Medicine, Universiti Teknologi MARA, 47000 Sungai Buloh, Selangor, Malaysia \\ ${ }^{2}$ Centre for Translational Research and Epidemiology (CenTRE), Faculty of Medicine, Universiti Teknologi MARA, \\ 47000 Sungai Buloh, Selangor, Malaysia \\ ${ }^{3}$ Population Health \& Preventive Medicine Discipline, Faculty of Medicine, Universiti Teknologi MARA, \\ 47000 Sungai Buloh, Selangor, Malaysia \\ ${ }^{4}$ Physiology Discipline, Faculty of Medicine, Universiti Teknologi MARA, 47000 Sungai Buloh, Selangor, Malaysia \\ ${ }^{5}$ Centre for Pathology \& Diagnostic Research Laboratory (CPDRL), Faculty of Medicine, Universiti Teknologi MARA, \\ 47000 Sungai Buloh, Selangor, Malaysia \\ ${ }^{6}$ Cardiology Discipline, Faculty of Medicine, Universiti Teknologi MARA, 47000 Sungai Buloh, Selangor, Malaysia
}

Correspondence should be addressed to Anis Safura Ramli; rossanis_yuzadi@yahoo.co.uk

Received 28 April 2013; Accepted 22 June 2013

Academic Editor: Leo J. Schouten

Copyright (C) 2013 Anis Safura Ramli et al. This is an open access article distributed under the Creative Commons Attribution License, which permits unrestricted use, distribution, and reproduction in any medium, provided the original work is properly cited.

\begin{abstract}
Metabolic syndrome (MetS) is a steering force for the cardiovascular diseases epidemic in Asia. This study aimed to compare the prevalence of MetS in Malaysian adults using NCEP-ATP III, IDF, and JIS definitions, identify the demographic factors associated with MetS, and determine the level of agreement between these definitions. The analytic sample consisted of 8,836 adults aged $\geq 30$ years recruited at baseline in 2007-2011 from the Cardiovascular Risk Prevention Study (CRisPS), an ongoing, prospective cohort study involving 18 urban and 22 rural communities in Malaysia. JIS definition gave the highest overall prevalence (43.4\%) compared to NCEP-ATP III (26.5\%) and IDF (37.4\%), $P<0.001$. Indians had significantly higher age-adjusted prevalence compared to other ethnic groups across all MetS definitions (30.1\% by NCEP-ATP III, $50.8 \%$ by IDF, and $56.5 \%$ by JIS). The likelihood of having MetS amongst the rural and urban populations was similar across all definitions. A high level of agreement between the IDF and JIS was observed (Kappa index $=0.867$ ), while there was a lower level of agreement between the IDF and NCEP-ATP III (Kappa index = 0.580). JIS definition identified more Malaysian adults with MetS and therefore should be recommended as the preferred diagnostic criterion.
\end{abstract}

\section{Introduction}

Metabolic syndrome (MetS), which is also known as "Syndrome X," was first described by Reaven in his 1988 Banting Lecture [1]. It is characterized by clustering of cardiovascular risk factors, namely, central obesity, elevated blood pressure, elevated plasma glucose, and dyslipidaemia [2]. Insulin resistance and adipose tissue dysfunction are thought to be the primary mediators of MetS $[3,4]$.

Since it was first introduced, MetS has become the subject of paramount research interest and also a subject of ongoing debate with regard to its clinical value as a distinct diagnostic 
entity $[5,6]$. Nevertheless, several diagnostic criteria for MetS continued to emerge over the last few decades. The first definition was introduced by the World Health Organization (WHO) in 1998 [7] followed by the National Cholesterol Education Program Expert Panel on Detection, Evaluation, and Treatment of High Blood Cholesterol in Adults (NCEPATP III) in 2001 [8]. Subsequently, the International Diabetes Federation (IDF) established a new worldwide definition for MetS in 2005 [9]. In contrast to the previous definitions, IDF made abdominal obesity a mandatory criterion using waist circumference (WC) cut-points based on gender and ethnicity [9]. In the same year, the NCEP-ATP III was modified to incorporate a lower fasting glucose threshold of $\geq 5.6 \mathrm{mmol} / \mathrm{L}$ and the same WC criteria as proposed by the IDF for Asians living in the United States [10]. However, the modified NCEP-ATP III maintained that the diagnosis of MetS should be made based on the presence of any 3 out of 5 risk factors. After several years of continuing debate and discussion, the various stakeholders finally agreed to harmonize the definition. A Joint Interim Statement (JIS) on MetS definition was issued in 2009 by the IDF Task Force on Epidemiology and Prevention; National Heart, Lung, and Blood Institute; American Heart Association; World Heart Federation; International Atherosclerosis Society; and International Association for the Study of Obesity [11]. The JIS committee agreed that the presence of any 3 out of 5 risk factors constitutes a diagnosis of MetS. Abdominal obesity is no longer a prerequisite for diagnosis, as more evidence is needed to relate WC with the risk of developing type 2 diabetes mellitus (T2DM) and cardiovascular diseases (CVD) [11]. Long-term prospective studies are also required to establish more reliable WC cut-points for different ethnic groups [11]. In the interim, the committee proposed that the WC cutpoints as recommended by IDF are used until new evidence emerges [11]. The new JIS "harmonized" definition is expected to have the advantage of identifying a larger number of MetS cases in a population, compared to the other definitions. Table 1 shows the summary of NCEP-ATP III, IDF, modified NCEP-ATP III, and JIS definitions for MetS.

Robust evidence showed that individuals diagnosed with MetS using these definitions have a greater risk of significant clinical consequences, the two most prominent of which are the development of T2DM and CVD [12-15]. Individuals with MetS have a fivefold greater risk of developing T2DM [12], while a systematic review of 37 studies involving more than 170,000 patients has shown that MetS doubles the risk of cardiovascular events [15].

Irrespective of the diagnostic criteria used, epidemiological studies from various parts of the world have clearly demonstrated that MetS is an increasing global health problem, not only in the western societies, but also in the Asian populations $[16,17]$. The clustering of CVD risk factors that characterizes MetS is a powerful driving force for the emerging CVD epidemic in Asia [17, 18]. The prevalence of MetS in East Asia was found to range from $8 \%$ to $13 \%$ in men and from $2 \%$ to $18 \%$ in women, depending on the population and definition used [17]. In Malaysia, epidemiological evidence describing prevalence of MetS is still scarce. Most local studies on MetS prevalence involved small sample size [19,
20 ], with the exception of a cross-sectional survey involving 4341 Malaysian adults (>18 years old) [21]. The survey showed that crude prevalence of MetS using WHO, NCEP-ATP III, IDF, and JIS definitions was $32.1 \%, 34.3 \%, 37.1 \%$, and $42.5 \%$, respectively [21]. More evidence is needed to describe the prevalence of MetS in Malaysia. This study aimed to compare the overall and age-adjusted prevalence of MetS in Malaysian adults using the NCEP-ATP III, IDF, and JIS definitions, identify the demographic factors associated with MetS, and determine the level of agreement between these definitions.

\section{Methods}

2.1. Study Design and Population. The Cardiovascular Risk Prevention Study (CRisPS) is an ongoing, prospective, community-based, cohort study involving Malaysian adults $\geq 30$ years of age from 18 urban and 22 rural communities from the states of Selangor, Negeri Sembilan, Pahang, Kelantan, and Sabah.

Subjects in CRisPS were selected in a four-stage sampling process: selecting the states and then "communities," followed by households within them and finally individuals within households. This design enables identification of both individual and environmental determinants of health.

2.2. Sampling Methods: State and Site Selection. The 5 states were pragmatically chosen to ensure adequate representation of the major ethnic groups in Malaysia. The main ethnic groups in Peninsular Malaysia are Malays, Chinese, and Indian, while the main ethnic groups in Sabah are the Kadazan-Dusun, Bajau, and Murut. For the purpose of this study, the Kadazan-Dusun, Bajau, Murut, and several other ethnic minorities were categorized as the indigenous groups. Selangor, Negeri Sembilan, and Pahang have a good mixture of Malay, Chinese, and Indian populations. Kelantan offers a predominant Malay population while Sabah represents the indigenous population. Figure 1 shows the map of CRisP Study sites illustrating the distribution of the urban and rural communities across the 5 states.

Community was defined as groups of people residing in the same locality who have common characteristics such as culture, socioeconomics, and use of amenities, goods, and services. Urban and rural areas were defined according to the Malaysian Population and Housing Census (2000) [22]. Gazetted areas with a combined population of 10,000 or more were defined as urban areas, while areas with a population of less than 10,000 were classified as rural.

Both urban and rural communities were selected with the aim of achieving within-community homogeneity in demographic and socioeconomic profiles. In view of the fact that this study was designed as a prospective cohort study, these communities were also selected based on the pragmatic requirement of optimizing the capacity of investigators to maintain long-term follow-up of participants and cooperation by community leaders. These factors were important to ensure continuity of data collection which is being scheduled every 3 years, for a period of 15 years. 
TABLE 1: Diagnostic criteria for metabolic syndrome.

\begin{tabular}{|c|c|c|c|c|}
\hline Risk factors (RF) & NCEP-ATP III (2001) & IDF (2005) & $\begin{array}{l}\text { Modified NCEP-ATP III } \\
(2005)\end{array}$ & JIS (2009) \\
\hline $\begin{array}{l}\text { Waist circumference } \\
\text { (WC) }\end{array}$ & $\begin{array}{l}\mathrm{M} \geq 102 \mathrm{~cm} \mathrm{~F} \geq 88 \mathrm{~cm} \\
\text { (Caucasian cut-points) }\end{array}$ & $\begin{array}{l}\mathrm{M} \geq 90 \mathrm{~cm} \mathrm{~F} \geq 80 \mathrm{~cm} \\
\text { (South Asian cut-points) }\end{array}$ & $\begin{array}{l}\mathrm{M} \geq 90 \mathrm{~cm} \mathrm{~F} \geq 80 \mathrm{~cm} \\
\text { (Asian cut-points) }\end{array}$ & $\begin{array}{l}\mathrm{M} \geq 90 \mathrm{~cm} \mathrm{~F} \geq 80 \mathrm{~cm} \\
\text { (South Asian cut-points) }\end{array}$ \\
\hline Blood pressure (BP) & $\begin{array}{l}\text { Systolic } \mathrm{BP} \geq 130 \text { and/or } \\
\text { diastolic } \mathrm{BP} \geq 85 \mathrm{mmHg}\end{array}$ & $\begin{array}{l}\text { Systolic } \mathrm{BP} \geq 130 \text { and/or } \\
\text { diastolic } \mathrm{BP} \geq 85 \mathrm{mmHg} \text { or } \\
\text { on treatment for HPT }\end{array}$ & $\begin{array}{l}\text { Systolic } \mathrm{BP} \geq 130 \text { and/or } \\
\text { diastolic } \mathrm{BP} \geq 85 \mathrm{mmHg} \text { or } \\
\text { on treatment for HPT }\end{array}$ & $\begin{array}{l}\text { Systolic } \mathrm{BP} \geq 130 \mathrm{and} / \text { or } \\
\text { diastolic } \mathrm{BP} \geq 85 \mathrm{mmHg} \text { or } \\
\text { on treatment for HPT }\end{array}$ \\
\hline $\begin{array}{l}\text { Fasting plasma } \\
\text { glucose (FPG) }\end{array}$ & $\geq 6.1 \mathrm{mmol} / \mathrm{L}$ & $\begin{array}{l}\geq 5.6 \mathrm{mmol} / \mathrm{L} \text { or previously } \\
\text { diagnosed T2DM }\end{array}$ & $\begin{array}{l}\geq 5.6 \mathrm{mmol} / \mathrm{L} \text { or on } \\
\text { treatment for elevated } \\
\text { glucose }\end{array}$ & $\begin{array}{l}\geq 5.6 \mathrm{mmol} / \mathrm{L} \text { or on } \\
\text { treatment for elevated } \\
\text { glucose }\end{array}$ \\
\hline Triglycerides (TG) & $\geq 1.7 \mathrm{mmol} / \mathrm{L}$ & $\begin{array}{l}\geq 1.7 \mathrm{mmol} / \mathrm{L} \text { or on treatment } \\
\text { for } \mathrm{TG}\end{array}$ & $\begin{array}{l}\geq 1.7 \mathrm{mmol} / \mathrm{L} \text { or on } \\
\text { treatment for } \mathrm{TG}\end{array}$ & $\begin{array}{l}\geq 1.7 \mathrm{mmol} / \mathrm{L} \text { or on } \\
\text { treatment for TG }\end{array}$ \\
\hline HDL-C & $\begin{array}{l}\mathrm{M}<1.03 \mathrm{mmol} / \mathrm{L} \\
\mathrm{F}<1.29 \mathrm{mmol} / \mathrm{L}\end{array}$ & $\begin{array}{l}\mathrm{M}<1.03 \mathrm{mmol} / \mathrm{L} \\
\mathrm{F}<1.29 \mathrm{mmol} / \mathrm{L} \text { or on } \\
\text { treatment } \\
\text { for HDL-C }\end{array}$ & $\begin{array}{l}\mathrm{M}<1.03 \mathrm{mmol} / \mathrm{L} \\
\mathrm{F}<1.29 \mathrm{mmol} / \mathrm{L} \text { or on } \\
\text { treatment for HDL-C }\end{array}$ & $\begin{array}{l}\mathrm{M}<1.0 \mathrm{mmol} / \mathrm{L} \\
\mathrm{F}<1.3 \mathrm{mmol} / \mathrm{L} \text { or on } \\
\text { treatment for } \mathrm{HDL}-\mathrm{C}\end{array}$ \\
\hline $\begin{array}{l}\text { Metabolic syndrome } \\
\text { definitions }\end{array}$ & At least $3 \mathrm{RF}$ & $\mathrm{WC}+2$ or more $\mathrm{RF}$ & At least $3 \mathrm{RF}$ & At least $3 \mathrm{RF}$ \\
\hline
\end{tabular}

RF: risk factors.

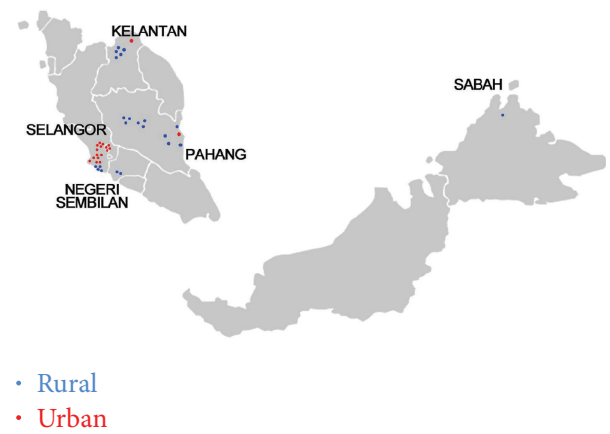

FIgure 1: The Cardiovascular Risk Prevention Study (CRisPS) sites map.

\subsection{Sampling Methods: Subjects Recruitment. A standardized} method of recruitment was adopted, in which announcements and invitations were made through local community leaders. All household members aged $\geq 30$ years residing in each locality were invited to attend a screening session at their local community centre through written invitation. Participants were given information regarding the purpose of the study and were requested to fast for at least 8 hours prior to the screening. A response rate of $60-70 \%$ was recorded for each site. At the screening centre, subjects were screened for eligibility. They were given an information leaflet regarding the study, and written informed consent was obtained.

The study protocol was approved by the institutional ethics committee.

2.4. Study Procedures. All interviewers and investigators were trained regarding the study procedures prior to the conduct of the study to minimize variability in the method of data collection. Standardized, interviewer-based questionnaires were used to collect information regarding age, gender, ethnic group, and educational attainment.
Anthropometrical measures which included waist circumference (WC) and blood pressure (BP) were obtained. WC was measured to the nearest $0.1 \mathrm{~cm}$ by using nonstretchable measuring tape with the subjects standing in a relaxed position and arms at the side. The measurement was taken at the midpoint between the lower rib margin (12th rib) and the iliac crest. BP was measured twice 2 minutes apart on the right arm in sitting position, using Omron automatic digital blood pressure monitor (Omron HEM757). Subjects were advised not to smoke, exercise, or eat in the last 30 minutes and not to climb stairs in the last 15-30 minutes and were made to rest for at least 5 minutes before the measurements were taken. Subjects were seated upright with his/her right arm supported at heart level. The average of the first and second measurements was used as the BP value for individual subjects. If the measurements differ by $5 \mathrm{mmHg}$ of either systolic or diastolic readings, subsequent measurements were taken at 5-10 minutes apart. The process was repeated until two BP values which did not differ by more than $5 \mathrm{mmHg}$ of either systolic or diastolic readings were obtained. The average of these two BP readings was used as the $\mathrm{BP}$ value for that particular subject.

Fasting venous blood samples were collected for plasma glucose and serum lipid profile (total cholesterol (TC), triglycerides (TG), low-density lipoprotein cholesterol (LDL$\mathrm{C})$, and high-density lipoprotein cholesterol [HDL-C]). TG, TC, HDL-C, and glucose levels were measured by enzymatic reference method on an automated analyzer (Cobas Integra 400 plus, Roche Diagnostic, Basel, Switzerland).

2.5. Metabolic Syndrome Definitions. MetS was defined according to 3 sets of criteria proposed by the NCEP-ATP III 2001 [8], IDF 2005 [9], and JIS 2009 [11] as previously shown in Table 1. Instead of the modified NCEP-ATP III 2005 [10], the first version of NCEP-ATP III 2001 which applied Caucasian cut-points for WC was chosen to define MetS for the purpose of this paper as it allows better comparison with 
other western studies. Furthermore, the MetS criteria in the modified NCEP-ATP III 2005 are very similar to those in JIS 2009. Consequently, the analysis using these two definitions yielded similar results. Therefore, the modified NCEP-ATP III 2005 definition was excluded as it does not add further value to this paper.

2.6. Data Collection. The baseline data was collected from 2007 to 2011, and follow-up data is currently being collected every 3 years for a period of 15 years. The analytic sample presented in this paper consisted of 8,836 subjects who were recruited at baseline.

2.7. Statistical Analysis. All data were entered and analyzed using STATA software version 11.1. Numerical variables were described with mean $( \pm$ Standard Deviation $(S D))$. Categorical variables were described with frequency and percentage. Age-adjusted prevalence was computed using direct standardization method and presented with 95\% CI. Multiple logistic regressions were used to determine the association between MetS according to the various definitions and the site of dwelling, age, gender, ethnicity, and educational attainment. Sensitivity, specificity, and level of agreement using Kappa index were determined for MetS diagnoses as defined by the NCEP-ATP III and JIS definitions, against the IDF definition. Significance level was set at $P$ value of $<0.05$.

\section{Results}

A total of 8,836 adults (mean age $53.21 \pm 10.6$ ) participated in this study. The sociodemographic characteristics of the study subjects are shown in Table 2 . It is noted that there were higher percentages of urban compared to rural populations and more females compared to male participants. With regard to ethnic group distributions, Malays comprised $72.5 \%$, Chinese $12.3 \%$, Indians 3.2\%, and indigenous groups $12.0 \%$ of the study population. More than a third of the participants attained secondary education and about a fifth attained tertiary educational level.

Table 3 shows the overall and age-adjusted prevalence of MetS according to the NCEP-ATP III, IDF, and JIS definitions by location, gender, ethnic group, and education attainment. JIS definition gave the highest overall prevalence $(43.4 \%)$ compared to IDF (37.4\%) and NCEP-ATP III (26.5\%). There was significantly higher age-adjusted prevalence of MetS in the urban compared to the rural population according to the IDF $(39.0 \%$ versus $36.3 \%, P=0.002)$ and JIS $(44.6 \%$ versus $42.5 \%, P=0.018$ ). In comparison to males, female participants had significantly higher age-adjusted prevalence according to the NCEP-ATP III (24.1\% versus $28.9 \%, P<$ $0.001)$ and $\operatorname{IDF}(36.1 \%$ versus $39.3 \%, P=0.001)$ but not significant according to the JIS definition (43.8\% versus $43.9 \%, P=0.777)$. The Chinese had the lowest age-adjusted prevalence according to the NCEP-ATP III definition (15.4\%, $P<0.001$ ), while the indigenous groups had the lowest ageadjusted prevalence by IDF $(26.3 \%, P<0.001)$ and JIS (32.5\%, $P<0.001)$ definitions. Indians had significantly higher age-adjusted prevalence compared to other ethnic groups by all MetS definitions $(30.1 \%$ by NCEP-ATP III,
TABLE 2: Demographic characteristics of the study subjects.

\begin{tabular}{lc}
\hline Demographic characteristics & \\
\hline All subjects, $n(\%)$ & $8836(100)$ \\
Mean age in years $( \pm$ SD) & $53.21( \pm 10.6)$ \\
Location, $n(\%)$ & $4757(53.8)$ \\
$\quad$ Urban & $4079(46.2)$ \\
$\quad$ Rural & \\
Gender, $n(\%)$ & $3766(42.6)$ \\
$\quad$ Male & $5070(57.4)$ \\
$\quad$ Female & \\
Ethnic group, $n(\%)$ & $6408(72.5)$ \\
$\quad$ Malays & $1085(12.3)$ \\
$\quad$ Chinese & $280(3.2)$ \\
$\quad$ Indians & $1063(12.0)$ \\
Indigenous groups & \\
Education attainment, $n(\%)$ & \\
$\quad$ No formal education & $1227(14.7)$ \\
$\quad$ Primary & $2182(26.1)$ \\
Secondary & $3236(38.7)$ \\
Tertiary & $1715(20.5)$ \\
\hline * Number not equal to $n=8836$ due to missing data $(n=8360)$
\end{tabular}

${ }^{*}$ Number not equal to $n=8836$ due to missing data $(n=8360)$.

$50.8 \%$ by IDF, and $56.5 \%$ by JIS). According to the NCEP-ATP III, those with tertiary education had the lowest age-adjusted prevalence $(19.5 \%, P<0.001)$. On the contrary, those with no formal education had the lowest age-adjusted prevalence by IDF definition $(32.3 \%, P=0.03)$.

Table 4 shows the association between MetS and the sociodemographic factors. The likelihood of having MetS amongst rural and urban populations was similar across all definitions. Female participants were found to be more likely to have MetS compared to males according to the NCEPATP III and IDF definitions but not by JIS definition. The likelihood of having MetS also increased with age where the odds ratio (OR) was highest in those aged $\geq 60$ years. With regard to ethnicity, Chinese and indigenous groups were found to be less likely to have MetS compared to the Malays across all definitions. Indians were found to be more likely to have MetS compared to the Malays according to the IDF and JIS definitions. In terms of education attainment, subjects with tertiary education were less likely to have MetS according to the NCEP-ATP III definition compared to those with no formal education. According to the IDF and JIS definitions, subjects with primary education were more likely to have MetS compared to those with no formal education.

Table 5 shows the sensitivity and specificity of MetS as defined by the NCEP-ATP III and JIS against IDF definition as the reference criteria for diagnosis. The NCEP-ATP III definition was only able to identify $60.7 \%$ as having MetS out of the total IDF defined cases. There was a high false negative rate at $39.3 \%$. The level of agreement as expressed by the Kappa index was 0.580 . The JIS definition was successful in diagnosing $99.4 \%$ of those diagnosed with MetS according to the IDF definition. The false negative rate was very low 
TABLE 3: The overall and age-adjusted prevalence of metabolic syndrome according to the NCEP-ATP III, IDF, and JIS definitions by location, gender, ethnic group, and education attainment.

\begin{tabular}{|c|c|c|c|c|}
\hline \multirow{2}{*}{ Demographic characteristics } & \multirow{3}{*}{$\begin{array}{c}\text { Total number of subjects } \\
8836\end{array}$} & NCEP-ATP III (2001) & IDF (2005) & JIS (2009) \\
\hline & & \multicolumn{3}{|c|}{ Prevalence (95\% confidence interval) } \\
\hline \multirow[t]{2}{*}{ Overall } & & $26.5(25.6-27.4)$ & $37.4(36.3-38.4)$ & $43.4(42.3-44.4)$ \\
\hline & & & $<0.001^{*}$ & \\
\hline \multicolumn{5}{|l|}{ Location } \\
\hline Urban & 4757 & $25.0(23.8-26.2)$ & $39.0(37.7-40.4)$ & $44.6(43.2-46.0)$ \\
\hline \multirow[t]{2}{*}{ Rural } & 4079 & $28.5(27.1-29.9)$ & $36.3(34.8-37.7)$ & $42.5(41.0-44.0)$ \\
\hline & & $0.001^{*}$ & $0.002^{*}$ & $0.018^{*}$ \\
\hline \multicolumn{5}{|l|}{ Gender } \\
\hline Male & 3766 & $24.1(22.7-25.4)$ & $36.1(34.6-37.7)$ & $43.8(42.3-45.4)$ \\
\hline \multirow[t]{2}{*}{ Female } & 5070 & $28.9(27.6-30.1)$ & $39.3(38.0-40.6)$ & $43.9(42.6-45.2)$ \\
\hline & & $<0.001^{*}$ & $0.001^{*}$ & 0.777 \\
\hline \multicolumn{5}{|l|}{ Ethnic group } \\
\hline Malays & 6408 & $29.1(28.0-30.2)$ & $40.2(39.1-41.4)$ & $46.0(44.8-47.1)$ \\
\hline Chinese & 1085 & $15.4(13.3-17.6)$ & $27.9(25.3-30.5)$ & $33.4(30.7-36.0)$ \\
\hline Indians & 280 & $30.1(25.3-34.9)$ & $50.8(45.6-56.0)$ & $56.5(51.4-61.7)$ \\
\hline \multirow[t]{2}{*}{ Indigenous groups } & 1063 & $20.7(18.5-23.2)$ & $26.3(23.6-29.1)$ & $32.5(29.6-35.4)$ \\
\hline & & $<0.001^{*}$ & $<0.001^{*}$ & $<0.001^{*}$ \\
\hline \multicolumn{5}{|l|}{ Education attainment } \\
\hline No formal education & 1227 & $25.4(22.6-28.2)$ & $32.3(29.2-35.4)$ & $39.8(36.6-43.0)$ \\
\hline Primary & 2182 & $29.4(27.4-31.3)$ & $38.5(36.4-40.5)$ & $44.4(42.3-46.6)$ \\
\hline Secondary & 3236 & $27.1(25.5-28.8)$ & $39.4(37.7-41.2)$ & $44.9(43.1-46.7)$ \\
\hline Tertiary & 1715 & $19.5(17.4-21.6)$ & $35.3(32.8-37.7)$ & $40.8(38.3-43.4)$ \\
\hline$P$ value & & $<0.001^{*}$ & $0.03^{*}$ & 0.362 \\
\hline
\end{tabular}

${ }^{*} P$ value $<0.05$.

at $0.6 \%$. The level of agreement between the JIS and IDF definitions was very good with a Kappa index of 0.867 .

\section{Discussion}

The CRisP Study reinforces the findings of a previous nationwide survey [21] that the overall prevalence of MetS among Malaysian adults was much higher compared with other Asian countries [17, 23]. This study found that the overall prevalence of MetS among Malaysian adults was 26.5\%, $37.4 \%$, and $43.4 \%$ according to the NCEP-ATP III, IDF, and JIS definitions, respectively. Comparison to other Asian countries can be made using the IDF definition (with similar WC cut-points), where the prevalence was much lower in Japan (11\%) [24], Singapore (17.7\%) [25], and Nepal (22.5\%) [26]. Comparison to other populations is harder to make as different WC cut-points were used to define abdominal obesity. MetS prevalence in the Greek population, however, was higher at $43.4 \%$ by IDF and $45.7 \%$ by JIS [27]. Similarly, prevalence by NCEP ATP III in the United States $(34.0 \%)$ [28] and Iran (34.7\%) [29] was much higher compared to the finding in the CRisP Study.

With regard to ethnicity, this study found that Malaysian Indians had significantly higher age-adjusted prevalence compared to other ethnic groups by all MetS definitions (30.1\% by NCEP-ATP III, $50.8 \%$ by IDF, and $56.5 \%$ by JIS). Another study also found that the prevalence in Asian Indians was high at $35.8 \%$ by NCEP-ATP III and $39.5 \%$ by IDF criteria [30]. It is well recognized that Indians, in particular of South Asian origin, have an ethnic predisposition to abdominal obesity, glucose intolerance, hypertension, and dyslipidaemia, resulting in increased morbidity and mortality rates due to CVD [31]. On the contrary, this study shows that Malaysian Chinese had the lowest MetS prevalence by NCEP-ATP III, while the indigenous groups had the lowest prevalence by IDF and JIS definitions. Malaysian Chinese and indigenous groups were also found to be less likely to have MetS compared to the Malays according to all definitions. Variations in the MetS prevalence in different ethnic groups living in the same country had also been shown in several other studies [32]. This variation may be due to the environmental and genetic factors, which have long been recognized to play a pivotal role in the pathophysiology of MetS [33].

As expected, the JIS definition gave the highest overall prevalence of MetS compared to NCEP-ATP III and IDF definitions. The JIS definition offers an advantage of identifying a larger number of individuals with MetS due to the presence of other multiple risk factors, despite having WC of less than the recommended cut-points. In this study, the likelihood of males being identified to have MetS was similar to females according to JIS definition, but female participants were found to be more likely to have MetS compared to males according to the NCEP-ATP III and IDF definitions. This 
TABLE 4: Factors associated with metabolic syndrome according to the ATP III, IDF, and JIS definitions among Malaysian adults $\geq 30$ years of age.

\begin{tabular}{|c|c|c|c|c|c|c|}
\hline \multirow{2}{*}{ Metabolic syndrome definitions } & \multicolumn{2}{|c|}{ NCEP-ATP III (2001) } & \multicolumn{2}{|c|}{ IDF (2005) } & \multicolumn{2}{|c|}{ JIS (2009) } \\
\hline & $\begin{array}{c}\text { Odds ratio } \\
(95 \% \text { CI })\end{array}$ & $P$ value & $\begin{array}{c}\text { Odds ratio } \\
(95 \% \text { CI })\end{array}$ & $P$ value & $\begin{array}{c}\text { Odds ratio } \\
(95 \% \text { CI })\end{array}$ & $P$ value \\
\hline \multicolumn{7}{|l|}{ Location } \\
\hline Urban & 1.00 & & 1.00 & & 1.00 & \\
\hline Rural & $1.06(0.94-1.20)$ & 0.326 & $0.87(0.79-1.02)$ & 0.086 & $0.89(0.80-1.00)$ & 0.058 \\
\hline \multicolumn{7}{|l|}{ Gender } \\
\hline Male & 1.00 & & 1.00 & & 1.00 & \\
\hline Female & $1.29(1.17-1.44)$ & $<0.001^{*}$ & $1.19(1.09-1.31)$ & $<0.001^{*}$ & $1.02(0.93-1.12)$ & 0.616 \\
\hline \multicolumn{7}{|l|}{ Age (years) } \\
\hline $30-39$ & 1.00 & & 1.00 & & 1.00 & \\
\hline $40-49$ & $1.39(1.13-1.73)$ & $<0.001^{*}$ & $1.63(1.35-1.97)$ & $<0.001^{*}$ & $1.56(1.30-1.87)$ & $<0.001^{*}$ \\
\hline $50-59$ & $2.26(1.83-2.79)$ & $<0.001^{*}$ & $2.72(2.25-3.27)$ & $<0.001^{*}$ & $2.72(2.27-3.25)$ & $<0.001^{*}$ \\
\hline$\geq 60$ & $2.34(1.87-2.92)$ & $<0.001^{*}$ & $2.67(2.18-3.26)$ & $<0.001^{*}$ & $3.08(3.54-3.70)$ & $<0.001^{*}$ \\
\hline \multicolumn{7}{|l|}{ Ethnicity } \\
\hline Malay & 1.00 & & 1.00 & & 1.00 & \\
\hline Chinese & $0.44(0.36-0.53)$ & $<0.001^{*}$ & $0.53(0.45-0.62)$ & $<0.001^{*}$ & $0.56(0.49-0.66)$ & $<0.001^{*}$ \\
\hline Indian & $1.02(0.77-1.37)$ & 0.867 & $1.48(1.14-1.92)$ & $0.003^{*}$ & $1.54(1.18-1.99)$ & $<0.001^{*}$ \\
\hline Indigenous groups & $0.60(0.50-0.72)$ & $<0.001^{*}$ & $0.56(0.47-0.66)$ & $<0.001^{*}$ & $0.63(0.54-0.73)$ & $<0.001^{*}$ \\
\hline \multicolumn{7}{|l|}{ Education level } \\
\hline No formal education & 1.00 & & 1.00 & & 1.00 & \\
\hline Primary & $1.16(0.99-1.37)$ & 0.067 & $1.34(1.15-1.58)$ & $<0.001^{*}$ & $1.18(1.01-1.37)$ & $0.029^{*}$ \\
\hline Secondary & $1.05(0.89-1.25)$ & 0.544 & $1.25(1.06-1.48)$ & $0.009^{*}$ & $1.12(0.96-1.31)$ & 0.147 \\
\hline Tertiary & $0.77(0.63-0.95)$ & $0.012^{*}$ & $1.04(0.86-1.27)$ & 0.673 & $0.92(0.76-1.10)$ & 0.350 \\
\hline
\end{tabular}

${ }^{*} P$ value $<0.05$.

TABLE 5: Sensitivity, specificity, and level of agreement for metabolic syndrome as defined by the NCEP-ATP III and JIS definitions against the IDF definition.

\begin{tabular}{|c|c|c|c|c|c|c|}
\hline \multirow{2}{*}{ Definitions } & \multicolumn{6}{|c|}{ IDF } \\
\hline & No MetS & Yes MetS & Sensitivity & Specificity & Kappa index & $P$ value \\
\hline \multicolumn{7}{|c|}{ NCEP-ATP III } \\
\hline No MetS & $5194(93.9 \%)$ & 1299 (39.3\%) & \multirow{2}{*}{$60.7 \%$} & \multirow{2}{*}{$93.9 \%$} & \multirow{2}{*}{0.580} & \multirow{2}{*}{$<0.001^{*}$} \\
\hline Yes MetS & 337 (6.1\%) & $2006(60.7 \%)$ & & & & \\
\hline \multicolumn{7}{|l|}{ JIS } \\
\hline No MetS & 4981 (90.1\%) & $19(0.6 \%)$ & \multirow{2}{*}{$99.4 \%$} & \multirow{2}{*}{$90.1 \%$} & \multirow{2}{*}{0.867} & \multirow[t]{2}{*}{$<0.001^{*}$} \\
\hline Yes MetS & $550(9.9 \%)$ & $3286(99.4 \%)$ & & & & \\
\hline
\end{tabular}

${ }^{*} P$ value $<0.05$.

may be explained by the fact that a higher number of males were diagnosed to have MetS according to the JIS definition, despite having WC of less than $90 \mathrm{~cm}$ (hence not classified as having MetS by IDF criteria). The ORISCAV-LUX study involving 1349 European subjects found that MetS prevalence by JIS definition was significantly higher in men than in women, as were all components of MetS except abdominal obesity [34]. A prospective analysis of mortality in men found that these males were still at high risk of CVD mortality due to the presence of multiple risk factors despite the absence of abdominal obesity [35]. A recent review has suggested that
JIS definition may better identify those at increased risk of CVD, while IDF definition may be more appropriate for the identification of those with insulin resistance and increased risk of T2DM [36].

In terms of location, this study shows that the likelihood of having MetS amongst the rural population was similar to their urban counterparts. The results are comparable to the NHMS III cohort study group whose data indicates that cardiovascular risk-factor clustering was similar in urban and rural populations [18]. The findings support the hypothesis that rapid economic development leads to urbanization of 
rural areas in Malaysia, resulting in the rural population adopting sedentary lifestyle, akin to their urban counterparts, and, therefore, have similar T2DM and CVD risks.

Consistent with the findings from another study [34], the CRisP Study also shows the likelihood of having MetS increased with age, where the OR was highest in those aged $\geq 60$ years. This is thought to be due to age-related rises of blood pressure and plasma glucose level [37]. Although Malaysia is still considered as a relatively young nation, its ageing population of $\geq 60$ years is rising steadily from $5.7 \%$ in 1990 to $6.3 \%$ in 2000 and is expected to be $9.8 \%$ in 2020 [38]. The increasing number of elderly population with multiple risk factors and comorbidities is poised to become a major challenge to the Malaysian healthcare system in the near future [39].

With regard to determining the level of agreement between the three definitions, IDF was used as the reference criterion as it is the most widely accepted in Malaysia. This study found a very high level of agreement between the JIS and IDF definitions (Kappa index $=0.867$ ). The finding is expected in view of similar reference range of the attributes including WC cut-points used in both definitions. On the contrary, there was a lower level of agreement (Kappa index $=0.580$ ) between NCEP-ATP III and IDF. This may be attributed to the difference in the reference ranges and WC cut-points in the NCEP-ATP III definition. Similarly, the ORISCAV-LUX study showed a remarkable level of agreement between the JIS and IDF definitions (Kappa index = 0.93 ), and lower level of agreement was found between NCEP-ATP III and IDF definitions (Kappa index $=0.84$ ) [34]. JIS should be recommended as the preferred diagnostic criterion as it shows a very high level of agreement with IDF and also has the advantage of identifying a larger number of individuals with MetS.

This study underlines the magnitude of cardiovascular risk factor clustering in the Malaysian population. The National Health and Morbidity Survey (2011) shows similar trend of escalating cardiovascular risk factor prevalence over the last two decades [40]. A higher MetS prevalence would translate into higher numbers with established diabetes, cardiovascular diseases, and events, leading to increased utilization of healthcare services, escalating health care costs, increased premature deaths, reduced productivity, and catastrophic economic implications [41]. This CVD epidemic has already begun in Malaysia where there is a trend towards a younger age at first myocardial infarction [42] and higher cardiovascular mortality than in developed countries [43].

MetS has now become a major public health threat and clinical problem. In response to the urgent needs to address this phenomenon, the Ministry of Health, Malaysia, launched the National Strategic Plan for the Non Communicable Disease (NSPNCD) in 2010, focusing on seven strategies which include prevention and health promotion, clinical interventions, partnership with patients, public engagement, research and surveillance, capacity building, and regulatory interventions [44]. However, when resources are limited, priorities should be given to the most cost-effective strategies which can produce swift changes [45]. At the public health level, more attention should be given to the modification of lifestyle of the general public through health promotion campaigns, multisectoral collaborations, and regulatory measures $[45,46]$. Preventive strategies should begin early in childhood as 3.9\% (0.3 million) of Malaysian children below 18 years were found to be obese [40]. Children who are obese have a greater likelihood of being obese in adulthood which would lead to the development of MetS, diabetes, and cardiovascular diseases [47]. Therefore, preventing obesity among young children is a vital strategy for reversing the epidemic [44]. The preschool and primary school years provide numerous opportunities to promote healthy eating and physical activity behaviors among children. Strategies which have been proven to be effective include integrating education on healthy eating, physical activity, and body image into classroom curriculum, increasing opportunities for physical activity throughout the school week, improving nutritional quality of the food supply in schools, engaging parents and promoting home activities, and supporting teachers to implement health promotion strategies [48]. Implementation of these interventions in Malaysian schools would require multisectoral collaborations between the education and health ministries. Regulatory measures should also include a requirement for the canteen operators to provide healthy food choices in Malaysian schools.

At the primary care level, individual patients with MetS need to be identified so that their multiple risk factors can be managed early to reduce complications [45]. Recent evidence from a middle income country has proven that treatment of multiple risk factors such as hypertension and dyslipidaemia had a much higher disability-adjusted life year (DALY) saved compared to enforced salt reduction in bread and tobacco cessation campaigns in mass media [49]. Concerted efforts should also be made to screen healthy individuals who are at risk of developing MetS. However, this attempt is often hampered by the shortage of multidisciplinary primary care team personnel in Malaysia [50]. Solutions therefore lie in enhancing the primary care delivery system and capacity building of primary care workforce $[45,50]$. The recently announced proposal by the Malaysian government to integrate all public and private primary care workforces under a common network of care, supported by the national health financing scheme, offers a promise of better coordination, continuity, and quality of care, especially to individuals with multiple risk factors [51].

4.1. Limitation. This study has several limitations. In contrast to other cross-sectional epidemiological studies where multistage stratified random sampling designs were used, this ongoing prospective cohort study pragmatically selected the urban and rural communities based on the feasibility for long-term follow-up and cooperation by the community leaders. The findings of this study, however, are similar and comparable to the findings of a previous nationwide survey using a two-stage stratified random sampling design [21].

Malaysia's ethnic population comprises $53.3 \%$ Malays, $26.0 \%$ Chinese, and $7.7 \%$ Indians, and the remaining $13 \%$ are of other ethnic groups [22]. Although measures had been taken to ensure adequate representation of the country's population, Malays were overrepresented, while Chinese and 
Indian populations were underrepresented in this study. However, the large sample size of this study population should counterbalance any possible bias in the sampling.

The possibility of determining which MetS definition better predicts adverse cardiovascular outcomes is also limited at this stage. The follow-up data of this ongoing prospective cohort study would be able to offer such findings in the future.

\section{Conclusion}

In conclusion, regardless of the definitions used, the CRisP Study indicates high MetS prevalence among Malaysian adults, much higher than in other Asian countries. Findings from this study underscore the urgency to stem the rising tide of MetS prevalence and the almost inevitable epidemic of T2DM and CVD in Malaysia. Public health measures, as well as individual intervention in primary care, are crucial to reduce their risk of developing T2DM and CVD. The JIS definition offers the advantage of identifying a larger number of individuals with MetS and should therefore be recommended as the preferred diagnostic criterion.

\section{Conflict of Interests}

The authors declare that they have no competing interests.

\section{Authors' Contribution}

A. S. Ramli wrote the paper and is involved in the design and coordination of the CRisP Study. A. M. Daher performed the statistical analysis and contributed to the critical discussion of the results. M. N. K. Nor-Ashikin, N. Mat-Nasir, K. K. Ng, M. Miskan, K. S. Ambigga, F. Ariffin, M. Y. Mazapuspavina, S. Abdul-Razak and H. Abdul-Hamid contributed to the critical revision of the paper. F. Abd-Majid and N. Abu-Bakar were involved in the coordination of the study. H. Nawawi verified the laboratory results and contributed to the critical revision of the paper. K. Yusoff is the Principal Investigator of this study. He played a major role in the conception and design of the study, contributed to the critical revision of the paper and intellectual content, and provided expertise and oversight throughout the process. All authors read and approved the final version.

\section{Acknowledgments}

This research is funded by the Ministry of Higher Education (Grant no. 600-RMI/LRGS 5/2 (2/2011)) and Ministry of Science, Technology and Innovation (Grant no. 07-05-IFN BPH 010). The authors acknowledge the following CRisPS Investigators for their contributions towards the study: Effarezan Abdul Rahman, Mohd Kamal Mohd Arsad, Mohd Yazrie Yacob, Rafezah Razali, Razif Dasiman, Rosiah Ahmad, Sarina Ali, Tengku Saifudin Tengku Ismail, and Zubin Othman Ibrahim. The authors also extend their appreciation to all participants, CenTRE, and CPDRL staff of the Faculty of Medicine, Universiti Teknologi MARA, for their contributions.

\section{References}

[1] G. M. Reaven, "Role of insulin resistance in human disease," Diabetes, vol. 37, no. 12, pp. 1595-1607, 1988.

[2] S. M. Grundy, "Metabolic syndrome: a multiplex cardiovascular risk factor," Journal of Clinical Endocrinology and Metabolism, vol. 92, no. 2, pp. 399-404, 2007.

[3] D. Lann and D. LeRoith, "Insulin resistance as the underlying cause for the metabolic syndrome," Medical Clinics of North America, vol. 91, no. 6, pp. 1063-1077, 2007.

[4] B. Gustafson, A. Hammarstedt, C. X. Andersson, and U. Smith, "Inflamed adipose tissue: a culprit underlying the metabolic syndrome and atherosclerosis," Arteriosclerosis, Thrombosis, and Vascular Biology, vol. 27, no. 11, pp. 2276-2283, 2007.

[5] P. M. Nilsson, "Cardiovascular risk in the metabolic syndrome: fact or fiction?" Current Cardiology Reports, vol. 9, no. 6, pp. 479-485, 2007.

[6] N. Sattar, A. McConnachie, A. G. Shaper et al., "Can metabolic syndrome usefully predict cardiovascular disease and diabetes? Outcome data from two prospective studies," The Lancet, vol. 371, no. 9628, pp. 1927-1935, 2008.

[7] K. G. Alberti and P. Z. Zimmet, "Definition, diagnosis and classification of diabetes mellitus, and its complications, part I: diagnosis and classification of diabetes mellitus provisional report of a WHO consultation," Diabetic Medicine, vol. 15, pp. 539-553, 1998.

[8] National Cholesterol Education Program (NCEP) Expert Panel on Detection, Evaluation, and Treatment of High Blood Cholesterol in Adults (Adult Treatment Panel III), "Third Report of the National Cholesterol Education Program (NCEP) Expert Panel on Detection, Evaluation, and Treatment of High Blood Cholesterol in Adults (Adult Treatment Panel III) final report," Circulation, vol. 106, pp. 3143-3421, 2002.

[9] K. G. Alberti, P. Zimmet, J. Shaw, and International Diabetes Federation (IDF) Epidemiology Task Force Consensus Group, "The metabolic syndrome: a new world- wide definition," The Lancet, vol. 366, pp. 1059-1062, 2005.

[10] S. M. Grundy, J. I. Cleeman, S. R. Daniels et al., "Diagnosis and management of the metabolic syndrome: An American Heart Association/National Heart, Lung, and Blood Institute scientific statement," Circulation, vol. 112, no. 17, pp. 2735-2752, 2005.

[11] K. G. M. M. Alberti, R. H. Eckel, S. M. Grundy et al., "Harmonizing the metabolic syndrome: a joint interim statement of the international diabetes federation task force on epidemiology and prevention; National Heart, Lung, and Blood Institute; American Heart Association; World Heart Federation; International Atherosclerosis Society; and International Association for the Study of Obesity," Circulation, vol. 120, no. 16, pp. 16401645, 2009.

[12] M. P. Stern, K. Williams, C. González-Villalpando, K. J. Hunt, and S. M. Haffner, "Does the metabolic-syndrome improve identification of individuals at risk of type 2 diabetes and/or cardiovascular disease?" Diabetes Care, vol. 27, no. 11, pp. 26762681, 2004.

[13] P. W. F. Wilson, R. B. D’Agostino, H. Parise, L. Sullivan, and J. B. Meigs, "Metabolic syndrome as a precursor of cardiovascular disease and type 2 diabetes mellitus," Circulation, vol. 112, no. 20, pp. 3066-3072, 2005.

[14] J. Sundström, U. Risérus, L. Byberg, B. Zethelius, H. Lithell, and L. Lind, "Clinical value of the metabolic syndrome for long term prediction of total and cardiovascular mortality: prospective, 
population based cohort study," British Medical Journal, vol. 332, no. 7546, pp. 878-882, 2006.

[15] A. S. Gami, B. J. Witt, D. E. Howard et al., "Metabolic syndrome and risk of incident cardiovascular events and death. A systematic review and meta-analysis of longitudinal studies," Journal of the American College of Cardiology, vol. 49, no. 4, pp. 403-414, 2007.

[16] S. M. Grundy, "Metabolic syndrome pandemic," Arteriosclerosis, Thrombosis, and Vascular Biology, vol. 28, pp. 629-636, 2008.

[17] W.-H. Pan, W.-T. Yeh, and L.-C. Weng, "Epidemiology of metabolic syndrome in Asia," Asia Pacific Journal of Clinical Nutrition, vol. 17, no. 1, pp. 37-42, 2008.

[18] S. Selvarajah, J. Haniff, G. Kaur et al., "Clustering of cardiovascular risk factors in a middle-income country: a call for urgency," European Journal of Preventive Cardiology, vol. 20, no. 2, pp. 368-375, 2013.

[19] H. M. Termizy and M. Mafauzy, "Metabolic syndrome and its characteristics among obese patients attending an obesity clinic," Singapore Medical Journal, vol. 50, no. 4, pp. 390-394, 2009.

[20] L. R. M. Zainuddin, N. F. Isa, W. M. Wan Muda, and H. J. Mohamed, "The prevalence of metabolic syndrome according to various definitions and hypertriglyceridemic-waist in Malaysian adults," International Journal of Preventive Medicine, vol. 2, no. 4, pp. 229-237, 2011.

[21] W. N. Mohamud, A. A. Ismail, A. Sharifuddin et al., "Prevalence of metabolic syndrome and its risk factors in adult Malaysians: results of a nationwide survey," Diabetes Research and Clinical Practice, vol. 96, no. 1, pp. 91-97, 2012.

[22] Department of Statistics Malaysia Census, "Changing patterns of utilization and analysis of population census data," in Proceedings of the 24th Population Census Conference, Hong Kong, China, March 2009, http://www.ancsdaap.org/cencon2009/ Papers/Malaysia/Malaysia.paper\%2Bappendix.pdf.

[23] P. Nestel, R. Lyu, P. L. Lip et al., "Metabolic syndrome: recent prevalence in East and Southeast Asian populations," Asia Pacific Journal of Clinical Nutrition, vol. 16, no. 2, pp. 362-367, 2007.

[24] C. M. Y. Lee, R. R. Huxley, M. Woodward et al., "Comparisons of metabolic syndrome definitions in four populations of the AsiaPacific region," Metabolic Syndrome and Related Disorders, vol. 6, no. 1, pp. 37-46, 2008.

[25] J. Lee, S. Ma, D. Heng et al., "Should central obesity be an optional or essential component of the metabolic syndrome? Ischemic heart disease risk in the Singapore cardiovascular cohort study," Diabetes Care, vol. 30, no. 2, pp. 343-347, 2007.

[26] S. K. Sharma, A. Ghimire, J. Radhakrishnan et al., "Prevalence of hypertension, obesity, diabetes, and metabolic syndrome in Nepal," International Journal of Hypertension, vol. 2011, Article ID 821971, 9 pages, 2011.

[27] V. G. Athyros, E. S. Ganotakis, K. Tziomalos et al., "Comparison of four definitions of the metabolic syndrome in a Greek (Mediterranean) population," Current Medical Research and Opinion, vol. 26, no. 3, pp. 713-719, 2010.

[28] R. B. Ervin, "Prevalence of metabolic syndrome among adults 20 years of age and over, by sex, age, race and ethnicity, and body mass index: United States, 2003-2006," National Health Statistics Reports, no. 13, pp. 1-7, 2009.

[29] A. Delavari, M. H. Forouzanfar, S. Alikhani, A. Sharifian, and R. Kelishadi, "First nationwide study of the prevalence of the metabolic syndrome and optimal cutoff points of waist circumference in the middle east: the national survey of risk factors for noncommunicable diseases of Iran," Diabetes Care, vol. 32, no. 6, pp. 1092-1097, 2009.

[30] M. Ravikiran, A. Bhansali, P. RaviKumar et al., "Prevalence and risk factors of metabolic syndrome among Asian Indians: a community survey," Diabetes Research and Clinical Practice, vol. 89, no. 2, pp. 181-188, 2010.

[31] A. Misra and L. Khurana, "The metabolic syndrome in South Asians: epidemiology, determinants, and prevention," Metabolic Syndrome and Related Disorders, vol. 7, no. 6, pp. 497-514, 2009.

[32] M. P. Reilly and D. J. Rader, "The metabolic syndrome: more than the sum of its parts?" Circulation, vol. 108, no. 13, pp. 15461551, 2003.

[33] P. Poulsen, A. Vaag, K. Kyvik, and H. Beck-Nielsen, "Genetic versus environmental aetiology of the metabolic syndrome among male and female twins," Diabetologia, vol. 44, no. 5, pp. 537-543, 2001.

[34] A. Alkerwi, A.-F. Donneau, N. Sauvageot et al., "Prevalence of the metabolic syndrome in Luxembourg according to the Joint Interim Statement definition estimated from the ORISCAVLUX study," BMC Public Health, vol. 11, article 4, 2011.

[35] P. T. Katzmarzyk, I. Janssen, R. Ross, T. S. Church, and S. N. Blair, "The importance of waist circumference in the definition of metabolic syndrome: prospective analyses of mortality in men," Diabetes Care, vol. 29, no. 2, pp. 404-409, 2006.

[36] C. M. Khoo, C. F. Liew, S. K. Chew, and E. S. Tai, “The impact of central obesity as a prerequisite for the diagnosis of metabolic syndrome," Obesity, vol. 15, no. 1, pp. 262-269, 2007.

[37] C. M. Alexander, P. B. Landsman, and S. M. Grundy, "The influence of age and body mass index on the metabolic syndrome and its components," Diabetes, Obesity and Metabolism, vol. 10, no. 3, pp. 246-250, 2008.

[38] M. Mafauzy, "The problems and challenges of the aging population of Malaysia," Malaysian Journal of Medical Sciences, vol. 7, pp. 1-3, 2000.

[39] K. S. Ambigga, A. S. Ramli, A. Suthahar, N. Tauhid, L. Clearihan, and C. Browning, "Bridging the gap in ageing: translating policies into practice in Malaysian primary care," Asia Pacific Family Medicine, vol. 10, no. 1, article 2, 2011.

[40] Institute for Public Health, Ministry of Health Malaysia, "The National Health and Morbidity Survey (NHMS) 2011: factsheet," Institute for Public Health, Ministry of Health Malaysia, Kuala Lumpur, Malaysia, 2012.

[41] J. Scholze, E. Alegria, C. Ferri et al., "Epidemiological and economic burden of metabolic syndrome and its consequences in patients with hypertension in Germany, Spain and Italy; a prevalence-based model," BMC Public Health, vol. 10, article 529, 2010.

[42] National Cardiovascular Disease Database, "Annual report of the NCVD-ACS registry Malaysia 2013," Tech. Rep., National Cardiovascular Disease Database, Kuala Lumpur, Malaysia, 2013.

[43] H. Ueshima, A. Sekikawa, K. Miura et al., "Cardiovascular disease and risk factors in Asia: a selected review," Circulation, vol. 118, no. 25, pp. 2702-2709, 2008.

[44] Non-Communicable Disease Section, Disease Control Division, Ministry of Health Malaysia, "National Strategic Plan for Non-Communicable Disease (NSPNCD): medium term strategic plan to further strengthen the cardiovascular diseases and diabetes prevention and control program in Malaysia (20102014)," Non-Communicable Disease Section, Disease Control Division, Ministry of Health Malaysia, Putrajaya, Malaysia, 2010. 
[45] WHO, "Preventing chronic diseases: a vital investment," World Health Organization, Geneva, Switzerland, 2005, http://www .who.int/chp/chronic_disease_report/full_report.pdf.

[46] S. Capewell and M. O'Flaherty, "Rapid mortality falls after riskfactor changes in populations," The Lancet, vol. 378, no. 9793, pp. 752-753, 2011.

[47] S. S. Guo, W. Wu, W. C. Chumlea, and A. F. Roche, "Predicting overweight and obesity in adulthood from body mass index values in childhood and adolescence," American Journal of Clinical Nutrition, vol. 76, no. 3, pp. 653-658, 2002.

[48] E. Waters, A. de Silva-Sanigorski, B. J. Hall et al., "Interventions for preventing obesity in children," Cochrane Database of Systematic Reviews, vol. 12, Article ID CD001871, 2011.

[49] A. Rubinstein, L. Colantonio, A. Bardach et al., "Estimation of the burden of cardiovascular disease attributable to modifiable risk factors and cost-effectiveness analysis of preventative interventions to reduce this burden in Argentina," BMC Public Health, vol. 10, article 627, 2010.

[50] A. S. Ramli and S. W. Taher, "Managing chronic diseases in the Malaysian primary health care-a need for change," Malaysian Family Physician, vol. 3, no. 1, pp. 7-13, 2008.

[51] New Straits Times, "Healthcare for FREE," 2010, http://www .malaysia-today.net/index.php?option=com_content $\& v i e w=$ article\&id=33023:healthcare-for-free\&catid=19:newscommentaries\&Itemid $=100131$. 


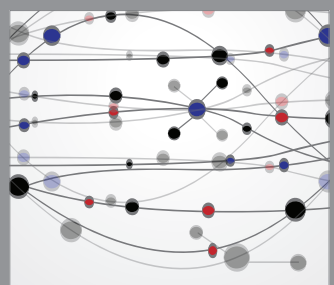

The Scientific World Journal
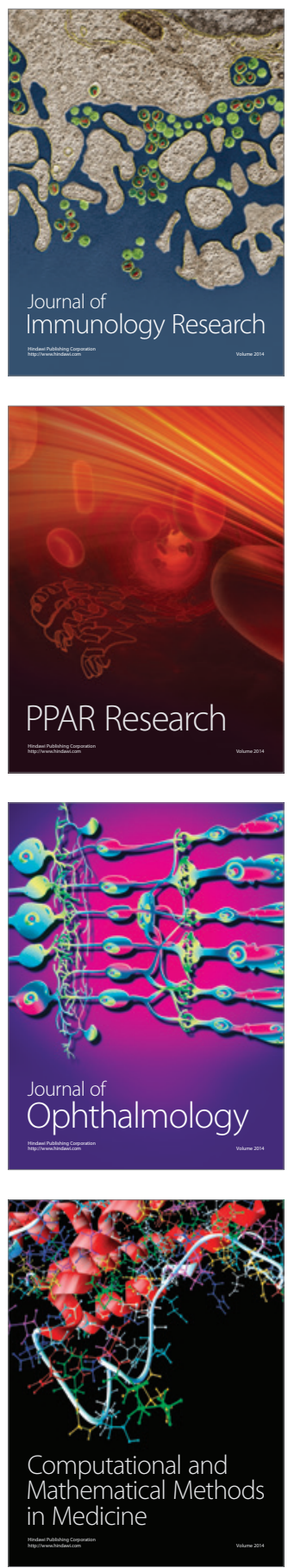

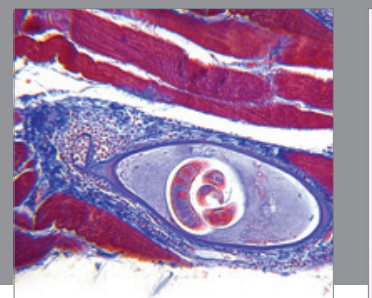

Gastroenterology

Research and Practice
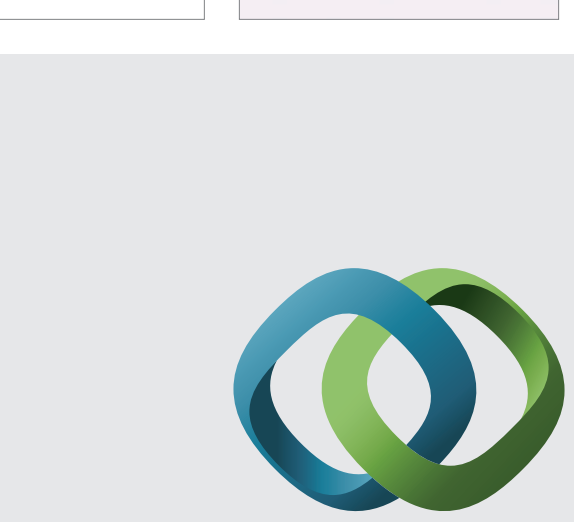

\section{Hindawi}

Submit your manuscripts at

http://www.hindawi.com
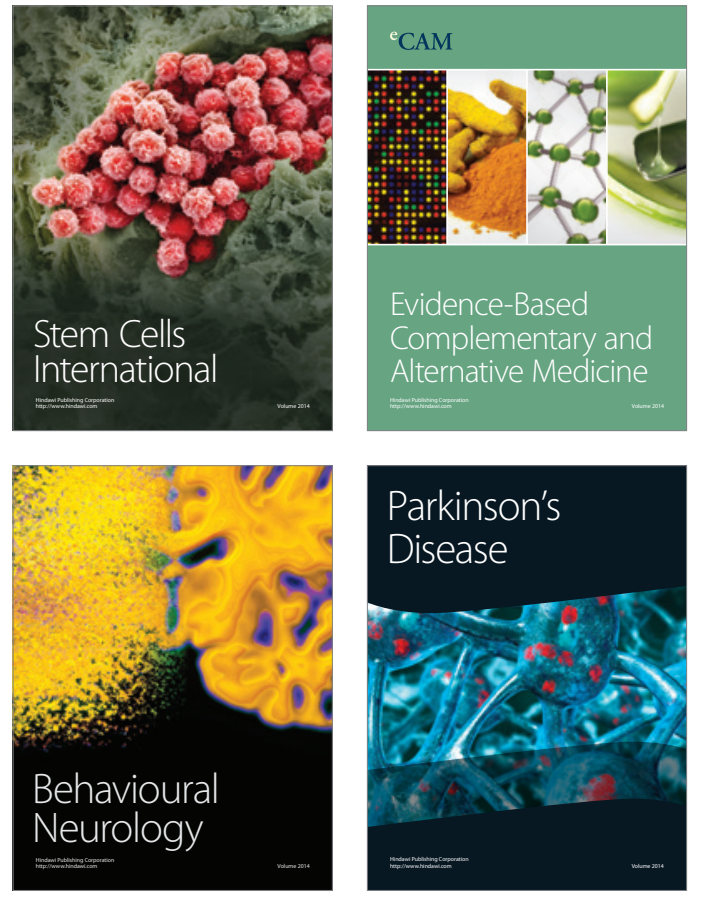
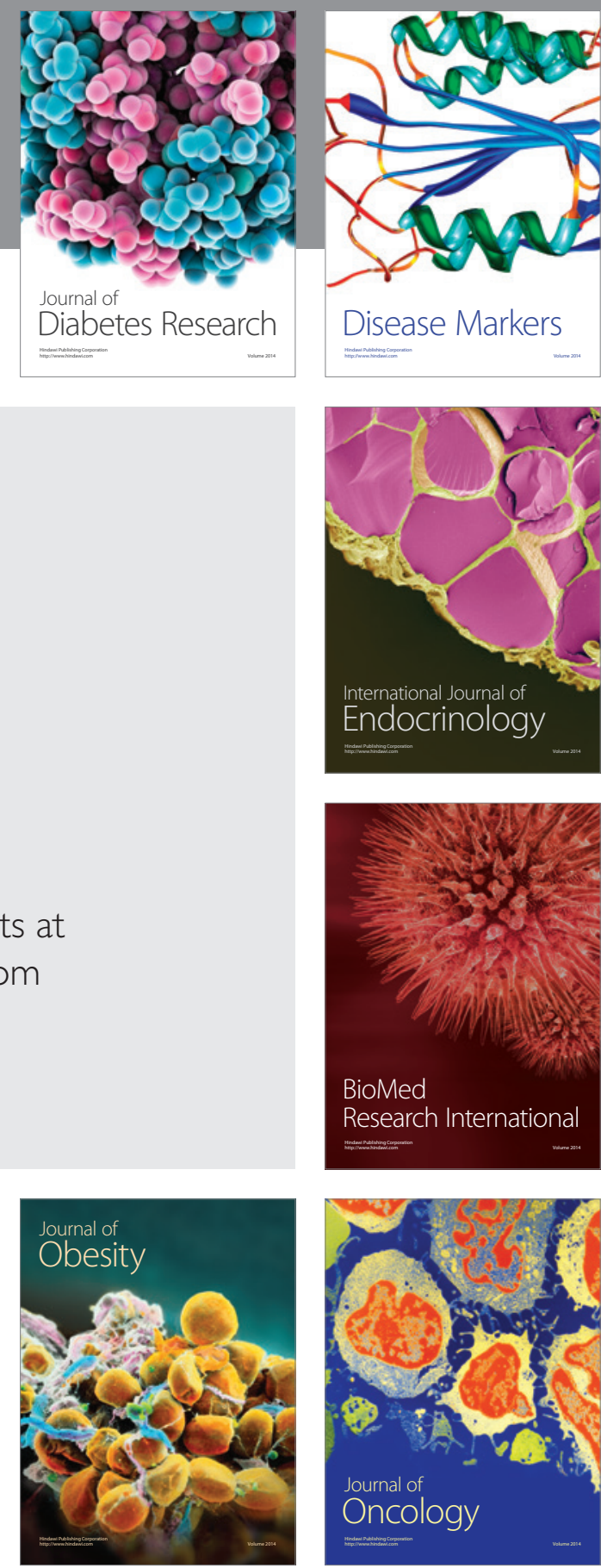

Disease Markers
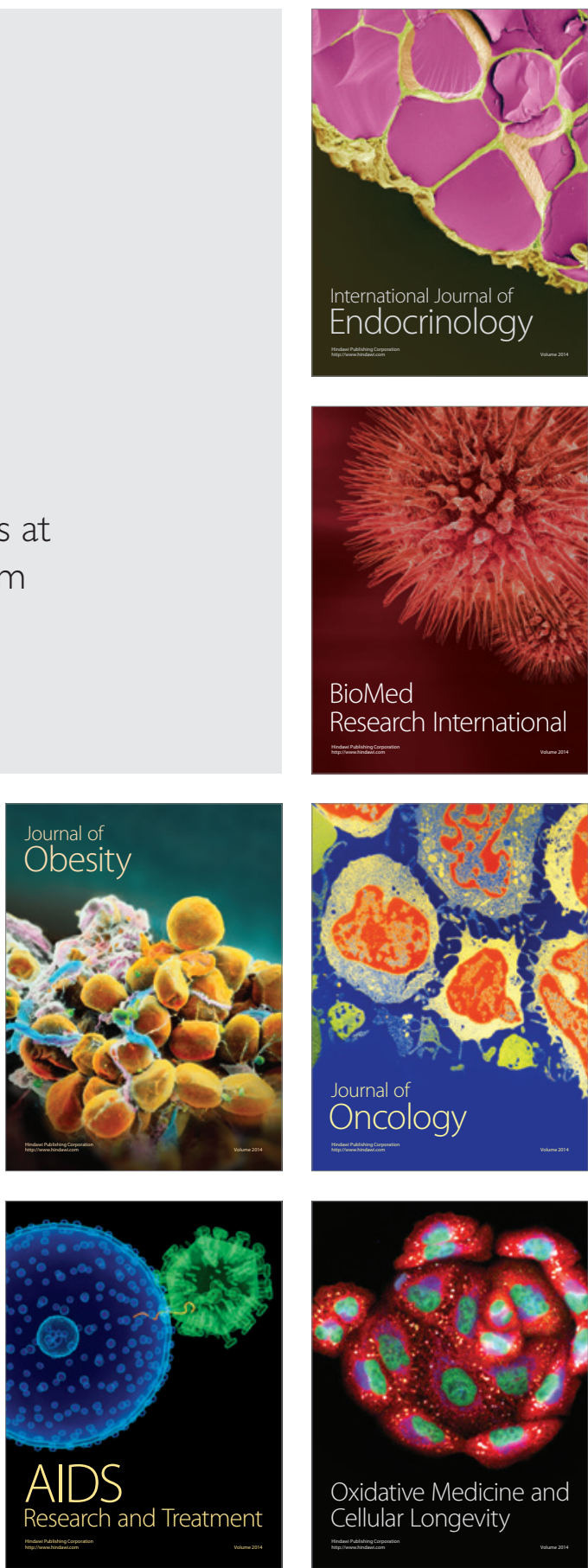